\title{
Vaping-associated lung injury-VALI facts, assumptions and opportunities: review of the present situation
}

\author{
Gabor Zoltan Xantus
}

\section{BACKGROUND}

More than 1400 respiratory cases have been linked to vaping at the Center for Disease Control and Prevention (CDC), one of the most prestigious epidemiological organisation in the world. So far, 33 patients succumbed to vaping-associated lung injury (VALI), a new syndrome characterised by respiratory distress with bilateral (sometimes haemorrhagic) infiltrates within 3 months of using e-cigarettes. VALI patients (mostly male young college or high school students) predominantly have presented with shortness of breath and gastrointestinal symptoms: majority needed hospital, often critical care admission. ${ }^{1}$ Vapes are batteryoperated devices that work by heating certain liquid compounds to produce vapours. Nicotine-containing liquids are mostly based on glycerine and/or propylene glycol to create dense fumes resembling cigarette smoke; however, cannabinoids are vaped in oil form (no fumes produced). The vapours are delivered to the lungs by inhalation, similar to smoking cigarette. Vaping devices are very different in terms of material of the coils, voltage used to heat the liquids, temperature of the inhaled aerosols and so far, no single culprit product has been identified. Until quite recently, e-cigarettes have been welcomed by most public health authorities and medical organisations all over the world, ${ }^{2-4}$ as they seemed to be a safer alternative to cigarette smoking. In countries where cannabis has been legalised vaporising cannabinoid oils became increasingly popular form of administration. However, the safety of vaping either nicotine-containing liquids or cannabinoid oils is yet unknown.

Is VALI a completely new disease, or a syndrome which has not yet reached critical mass to be recognised prior to the present surge of cases? To understand the background and to have a clear picture of the illness itself, we aim to report the

Correspondence to Dr Gabor Zoltan Xantus, Alumni, Cardiff University, Cardiff CF10 3XQ, UK; gabor.xantus@gmail.com facts in chronological order in broader perspective differentiating vaping nicotine and cannabinoid products, reviewing the safety and ethical aspects of both and briefly appraising the available studies.

\section{WHAT IS VALI?}

Since April 2019 reports came from numerous county hospitals in Illinois and Wisconsin of an unusual disease causes shortness of breath and gastrointestinal symptoms mostly among young college or high school students. In June, the public health authorities of the two states recognised a trend in the unusual cluster of steadily increasing respiratory distress cases. By July, the unusual presentations doubled compared with 2018, therefore the cluster of cases were reported to CDC. Within a month CDC collected over 250 cases with one fatality all over the USA, therefore on the 30 August CDC published a warning through its Healthcare Alert Network notifying both the public and the medical community of the potential association between vaping and a severe lung disease. ${ }^{5}$

At the moment, it seems that physical-chemical exposure may play pivotal, potentially causative role in the onset of VALI. Interestingly enough in a few cases researchers noted fatty deposits in certain patients' white cells, which have not been reported previously in acute respiratory distress syndrome, chemical pneumonitis or lipoid pneumonia. Seventy-eight per cent of the patients have reported to use tetrahydrocannabinol (THC)-containing products, 31\% reported using THC oils only; however, $22 \%$ of the patients used nicotine products alone. ${ }^{6}$

Vast majority (98\%) of the patients presented with respiratory symptoms; however, most $(81 \%)$ had gastrointestinal (diarrhoea and vomiting) problems as well. Almost one-third progressed rapidly to respiratory distress needing intubation and mechanical (mostly positive pressure) ventilation. Imaging often revealed bilateral infiltration; however, the pathology was very diverse, varied from chemical pneumonitis (with one case of lipoid pneumonia) to certain degree of acute respiratory distress syndrome with bilateral infiltrates (sometimes haemorrhage). ${ }^{7}$

\section{PRIME SUSPECTS OF AETIOLOGY}

It is not yet understood what component or components are responsible for the cluster of cases. It became apparent that most patients vaped cannabinoids; however, the source of the liquids is yet to be investigated. Federal and state investigators therefore are focusing on vape cartridges that likely contained THCthe psychoactive ingredient of cannabis. Appreciating the potential public health implications CDC is cooperating with the Forensic Laboratory of the FDA to analyse the seized samples.

An industry founded report of 102 legal and 12 illicit vaporisable cannabinoid oil samples identified numerous potentially harmful components (heavy metals, vitamin E-acetate, pesticides, fungicides and certain other thickening agents $)^{8}$; however, it may also be possible that the thermic activation of the oils may create new, potentially harmful chemicals. A recent testing by Flora Research Laboratories (Oregon, USA) ${ }^{9}$ commissioned by the Associated Press Health and Science Department (on 30 commercially available sample of legal CBD and THC cartridges) using high-performance liquid chromatography (the gold standard method for compound analysis) found synthetic marijuana in at least a third of the samples. Synthetic marijuana has been linked to deaths and adverse effects including psychosis and violence in users. ${ }^{10}$ The cannabidinol content in the analysed samples seemed inconsistent varying from $0 \%$ to $8.9 \%$.

Another investigation commissioned by National Broadcasting Company, 18 legal and illegal samples were analysed. The samples were analysed by CannaSafe Analytics LLC, the world first accredited cannabis laboratory. ${ }^{11}$ At least 10 samples had unacceptable level of pesticides and myclobutanil. Latter is a fungicide, which turns into the hydrogen cyanide and hydrogen chloride when heated: both compounds may result in lung damage if inhaled. ${ }^{12}$ Suspecting impurity of the illegal oils, CDC and the FDA has warned consumers not to buy THC oil from street dealers.

As nearly a quarter of cases used nicotine vapes only, authorities have expanded their research to all substances used in electronic cigarettes. To our present knowledge, nicotine vape fluids may also contain certain compounds with potential harmful 
properties (nicotine, carbonyl, benzene, toluene). Some of the otherwise approved flavours and thickening agents may also trigger to certain pathological changes in the airways; however, their clinical significance is yet unknown, ${ }^{13}$ therefore CDC in its most recent recommendation advised to refrain from vaping in general.

Fatalities do not follow clear geographical pattern whether marijuana being legal or illegal: California (fully legal), Indiana (CBD only) and Minnesota (medicinally legal) reported 3 fatal outcomes, Oregon (fully legal), Kansas (fully legal), Georgia (CBD only) reported 2 deaths and 18 other states (mixed legal status) reported 1 lethal outcome.

\section{SAFETY OF VAPING NICOTINE- CONTAINING LIQUIDS}

A recent recommendation by Public Health England in February 2019 specifically recommended to make e-cigarettes more available to the public to help smoking cessation $^{14}$ stating that 'Overall, England continues to take small progressive steps towards ensuring vaping remains an accessible and appealing alternative to smoking' and set up a task force to explore potential 'barriers to licensing and commercializing' of such products.

Vaping became increasingly popular in the USA, too. In 2018, the (nicotine) e-cigarette market was estimated to have reached US\$5.5 billion while the whole legal tobacco market was roughly US $\$ 125$ billion. FDA published clear rules 'clarifying tobacco products, drugs and/ or devices" ${ }^{15}$; however, a loophole in marketing and legislation allowed free advertising of e-cigarettes contrary to the promotion of cigarettes or other tobacco products. To date, at least three medicinally accepted products are marketed and await approval from the Centre for Drug Evaluation and Research of the Food and Drug Administration (FDA).

However, since 2017 prestigious professional bodies: the American Heart Association, the Australian Lung Foundation and the European Respiratory Society have seemed to be more conservative and announced reservation for the widespread and unregulated use of vaping. ${ }^{16-18}$ In September 2019, an in vitro study demonstrated decreased Tumor Necrosis factor $\alpha$ (TNF- $\alpha$ ) production in lung epithelium cell culture; however, its clinical relevance is yet unknown. ${ }^{19}$

\section{VAPING CANNABINOIDS: ETHICAL AND SAFETY CONCERNS}

In recent years, cannabinoids have seen an increase in prescribing triggered both by patient demand and decriminalisation of marijuana. Given the fact that cannabis and its derivatives has been outlawed for almost a century, the paucity of high-quality evidence is not surprising. However, regulating authorities are more and more open to discover new indications. Medical cannabis is legal in over 40 countries in the world, medical use comprises sublingual oils, tinctures, soft-gel capsules and flower vaporisers. There has been an abundance of clinical studies (unfortunately of variable quality); however, to date, vaporised oils have not been tried (at least published) in controlled clinical circumstances. So far, no vaporising device has been granted FDA approval for vaping medicinal cannabis in any form; however, in Canada and in Europe, there are products (licensed as medical device) available for vaping dried cannabis flowers for medicinal purposes. ${ }^{20} 21$

The conventional form of smoking cannabis or its derivatives is unwanted in medical practice due to its potentially damaging effect on the patients' and their close contact's health (secondhand smoking). As medical use of cannabis has partially been driven by patients it is not surprising that vaping became a popular form of self-medicating in various indications. Unlike nicotine vaping, there are no institutional/industrial guidelines or recommendations regarding vaping cannabis. Given the similar principles, however, recommendations and guidelines regarding vaping nicotine products might be inferential for cannabis vaping as well.

New drugs and/or delivery methods may take long time to come to market. Appreciating this delay (and respecting the human rights) regulatory agencies have tried to shorten the lag between identification and approval. ${ }^{22}$ The accelerated pathways recognise drugs and/or delivery methods developed to treat serious conditions ('morbidity that has substantial impact on day-to-day functioning') or unmet need ('a condition whose treatment or diagnosis is not addressed adequately by available therapy').

\section{VAPING CANNABIS: A CRITICAL APPRAISAL OF EVIDENCE}

The first cannabis (dry flower) vaporizer for clinical research was filed with the FDA in $2004 .{ }^{18}$ Following the hierarchy of evidence-based medicine, there have been numerous in vitro studies ${ }^{23}$ followed by in vivo, ethically approved observational and randomised clinical trials. ${ }^{24} 25$ A 2017 review concluded that although vaping cannabinoids might not necessarily be safe (especially risky in younger people and pregnancy) it might still be preferable 'for users and the environment, in comparison to smoking cannabis'. ${ }^{26}$ Obviously, future research is needed especially in areas of physical-chemical, toxicological, physiological, psychological-sociological and epidemiological medicine.

\section{SUMMARY}

VALI is a serious respiratory condition seemingly endemic to North America. Interestingly, so far similar cluster of cases have not been reported from other parts of the world; Canada reported one case only and none was seen in Europe or Australia. This extent of discrepancy cannot necessarily be explained by the differences of the surveillance systems, ${ }^{27}$ other causes may need to be investigated.

CDC has to date failed to identify one culprit component or product responsible for such grave respiratory symptoms. Interestingly, in the most recent update on VALI, CDC verified (by means of broncho-alveolar lavage) the presence of Vitamin E acetate in the lungs in at least 29 patients having vaped illicit THC containing oils however, there seems to be still no answer for the cases who vaped nicotine only products. ${ }^{6}$ The number of cases may warrant federal response; however, to date, only certain states have restricted the use of vaping. Massachusetts was the first to ban sales of any vapes (for 4 months), New York and Michigan soon followed. Even though no confirmed cases of VALI have been reported, however, outside the USA, other countries are trying to regulate the e-cigarette use. The Australian legislation agreed to commission an independent investigation by the National Centre for Epidemiology and Population Health at Australian National University. India banned the sales, import, advertising and production of e-cigarettes with immediate effect (however, does not sanction it use). China, via the State Tobacco Monopoly allegedly planning to control e-cigarette devices and packaging from October 2019. The cases highlighted the loopholes in marketing and legislation of nicotine-containing vapes, therefore the market leader Juulstopped all public advertising and marketing activities all over the world and his founder and CEO resigned with immediate effect. Some fear that the confirmed cases might actually be the tip of the iceberg.

In prevention information and patient education is probably the key. As patients predominantly presented first in 
emergency departments or urgent care centres, practices may consider sending out anonymous questionnaires (as means of secondary prevention) to patients who screened positive for e-cigarette use during their previous visits. Should vaping itself prove harmful it may cause landslide in the tobacco industry, the contrary, however, with proper regulations in place may open new avenues for research in medical cannabis.

Acknowledgements The author acknowledges the invaluable help of Samuel Banks in proofreading the manuscript.

Contributors GZX incepted the idea, performed the necessary background search (using Cardiff University search engine), wrote the manuscript and submitted the article.

Funding The authors have not declared a specific grant for this research from any funding agency in the public, commercial or not-for-profit sectors.

Competing interests None declared.

Patient consent for publication Not required.

Provenance and peer review Not commissioned; externally peer reviewed.

(c) Author(s) (or their employer(s)) 2020. No commercial re-use. See rights and permissions. Published by BMJ.

\section{D) Check for updates}

To cite Xantus GZ. Postgrad Med J 2020;96:61-63.

Received 27 September 2019

Revised 25 October 2019

Accepted 10 November 2019

Published Online First 25 November 2019

Postgrad Med I 2020;96:61-63.

doi:10.1136/postgradmedj-2019-137185

ORCID iD

Gabor Zoltan Xantus http://orcid.org/0000-0003-30600069

\section{REFERENCES}

1 Layden JE, Ghinai I, Pray I, et al. Pulmonary illness related to e-cigarette use in Illinois and Wisconsin - preliminary report. N Engl J Med 2019. doi:10.1056/ NEJMoa1911614. [Epub ahead of print: 6 Sep 2019]

2 Gov.uk. Vaping in England - an evidence update February 2019. Available: https://www.gov.uk/ government/publications/vaping-in-england-anevidence-update-february-2019

3 Rafi I. RCGP position statement on the use of electronic nicotine vapour products (E-cigarettes), 2017. Available: https://www.cancerresearchuk.org/ sites/default/files/rcgp_e-cig_position_statement_ approved_060917_clean_copy.pdf

4 Mathur A, Dempsey OJ. Electronic cigarettes: a brief update. J R Coll Physicians Edinb 2018;48:346-51.

5 CDC Health Alert Network. Centre for Disease Control and Prevention. Severe Pulmonary Disease Associated with using E-cigarette products [Online], 2019. Available: https://emergency.cdc.gov/han/han00421. asp

6 Centers for Disease Control. Outbreak of Lung Injury Associated with E-Cigarette Use, or Vaping, 2019. Available: https://www.cdc.gov/tobacco/basic information/e-cigarettes/severe-lung-disease.htm

7 Christiani DC. Vaping-Induced lung injury. N Eng/ J Med 2019. doi:10.1056/NEJMe1912032. [Epub ahead of print: 6 Sep 2019].

8 CannaSafe. Vitamin E-acetate report 2019. Available: https://csalabs.com/wp-content/uploads/2019/10/ CannaSafe VitaminEAcetate Report.pdf

9 Flora research laboratories, 2019. Available: http:// www.floraresearch.com pdf [Accessed 27 Sep 2019].

10 Center for Disease Control and Prevention. Synthetic cannabinoids: an overview for healthcare providers. Available: https://www.cdc.gov/nceh/hsb/chemicals/sc/ healthcare.html

11 CannaSafe analytics LLC, 2019. Available: https:// www.marijuanalabtesting.com/directory/listing/ cannasafe-analytics-\|lc-illinois

12 U.S. National Library of Medicine. Myclobutanil. Available: https://pubchem.ncbi.nlm.nih.gov/ compound/Myclobutanil\#section=Information-Sources

13 Cancer Prevention Research. Effects of electronic cigarette constituents on the human lung: a pilot clinical trial, 2019. Available: https://cancerprevention research.aacrjournals.org/content/canprevres/early/ 2019/10/11/1940-6207.CAPR-19-0400.full.pdf

14 NHS Scotland Health. Smoking 2019. Available: http:// www.healthscotland.scot/health-topics/smoking/ecigarettes pdf [Accessed 18 Sep 2019].

15 U.S. Department of Health and Human Services. Modifications to compliance policy for certain deemed tobacco products guidance for industry draft guidance, 2019. Available: https://www.fda.gov/media/121384/ download [Accessed 18 Sep 2019].
16 Bhatnagar A, Whitsel LP, Ribisl KM, et al. Electronic cigarettes. Circulation 2014;130:1418-36.

17 Bals R, Boyd J, Esposito S, et al. Electronic cigarettes: a task force report from the European respiratory Society. Eur Respir J 2019;53.

18 Thoracic Society of Australia and New Zealand and the Australian Lung Foundation. Inquiry into the use of electronic cigarettes and personal Vaporisers in Australia 2018. Available: https://lungfoundation.com. au/wp-content/uploads/2018/09/Information-paperInquiry-into-the-use-of-ecigarettes-and-personalvaporisers-in-Australia-Mar2018.pdf

19 Ween MP, Hamon R, Macowan MG, et al. Effects of e-cigarette E-liquid components on bronchial epithelial cells: demonstration of dysfunctional efferocytosis. Respirology 2019. doi:10.1111/resp.13696. [Epub ahead of print: 22 Sep 2019].

20 Health Canada. Volcano medic vaporizer, 2010 Available: https://health-products.canada.cal mdall-limh/information.do?deviceld idlnstrument= 547498\&deviceName_nominstrument=VOLCANO+ MEDIC\&lang=eng\&licenceld=82405 [Accessed 18 Sep 2019].

21 Health Canada. Resolve digital healths medical cannabis vaporizer, 2019. Available: https://www. newcannabisventures.com/health-canada-approvesresolve-digital-healths-medical-cannabis-vaporizer/ [Accessed 18 Sep 2019].

22 Center for Drug Evaluation and Research. Expedited programs for serious Conditions-Drugs and biologics, 2019. Available: https://www.fda.gov/regulatoryinformation/search-fda-guidance-documents/ expedited-programs-serious-conditions-drugs-andbiologics [Accessed 18 Sep 2019].

23 Lanz C, Mattsson J, Soydaner U, et al. Medicinal cannabis: in vitro validation of vaporizers for the smoke-free inhalation of cannabis. PLoS One 2016;11:e0147286.

24 Gieringer D, St. Laurent J, Goodrich S. Cannabis vaporizer combines efficient delivery of THC with effective suppression of pyrolytic compounds. Journal of Cannabis Therapeutics 2004;4:7-27.

25 van de Donk T, Niesters M, Kowal MA, et al. An experimental randomized study on the analgesic effects of pharmaceutical-grade cannabis in chronic pain patients with fibromyalgia. Pain 2019:160:860-9.

26 Singh D, Lippmann S. Vaping medical marijuana. Postgrad Med 2018;130:183-5.

27 Calba C, Goutard FL, Hoinville L, et al. Surveillance systems evaluation: a systematic review of the existing approaches. BMC Public Health 2015;15:448. 